\title{
Identifikasi Permasalahan Penjualan Dengan Metode SWOT Pada UKM Gula Merah
}

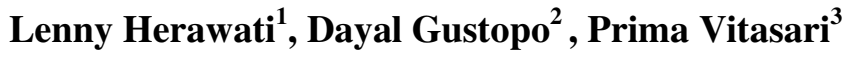 \\ ${ }^{1}$ Mahasiswa Pasca Sarjana Magister Teknik ITN Malang \\ ${ }^{2,3}$ Teknik Industri S2, Pascasarjana ITN Malang \\ E-mail: lennyherawati76@gmail.com
}

\begin{abstract}
Abstrak
Hasil produksi pada UKM ini adalah gula merah, dimana usaha kecil menengah seringkali menghadapi berbagai kendala dalam menjalankan usahanya.Tak terkecuali usaha gula merah milik UKM bapak Khoiru dimana usaha tersebut merubah produknya dari gula merah curah menjadi gula merah cetak.Beberapa kendala tersebut seperti persaingan semakin ketat, perubahan teknologi menjadikan permasalahan pada pemasaran produk gula merah. Tujuan penelitian ini adalah mengidentifikasi kondisi UKM saat ini .Populasi yang diambil dalam penelitian ini yaitu pekerja bagian produksi dan manajemen pada UKM. Metode penarikan sampel yang digunakan adalah random sampling yaitu pengambilan sampel anggota populasi yang dilakukan secara acak tanpa memperhatikan strata yang ada dalam populasi tersebut, Sampel dalam penelitian ini adalah 113 orang dengan perincian 100 orang konsumen dan 13 orang manajemen UKM. Metode yang digunakan dalam penelitian ini adalah analisis SWOT. Hasil penelitian menunjukkan bahwa identifikasi awal yaitu UKM pada kuadran 4, merupakan situasi yang sangat tidak menguntungkan dimana UKM menghadapi berbagai ancaman dan kelemahan internal.Posisi ini membuktikan bahwa UKM lemah dan menghadapi tantangan besar. Dari hasil identifikasi didapatkan angka nilai -171,6 untuk internal dan -133,65 untuk faktor eksternal. Nilai 171,6 diperoleh dari jumlah total nilai strength dikurangi jumlah total nilai weakness, angka -171,6 diperoleh dari jumlah total nilai opportunitydikurangi dengan jumlah total nilai threat.
\end{abstract}

Kata Kunci : Peningkatan penjualan, SWOT, Produk gula merah

\section{Pendahuluan}

Saat ini pertumbuhan perekonomian Negara sangat dipengaruhi oleh pertumbuhan jumlah penduduk yang sangat tinggi juga pelaku usaha (UKM). Disisi lain penerapan system otonomi daerah yang diserahkan secara sepenuhnya kepada masing-masing daerah membuat tiap daerah berlombalomba untuk mengembangkan wilayahnya dengan memanfaatkan seluruh potensi yang ada. Secaa nasional usaha kecil dan menengah mempunyai kedudukan, potensi dan peranan yang sangat penting dan strategis dalam rangka mewujudkan tujuan pembangunan nasional pada umumnya dan tujuan pembangunan ekonomi pada khususnya [1].Pada dasarnya UKM harus memiliki strategi dalam menjalankan setiap aktifitas usahanya agar dapat tercapainya tujuan yang diinginkan UKM. Melihat kondisi UKM dimasa lalu dan banyaknya ancaman yang timbul dari pesaing maka dapat dianalisis aspek-aspek internal (kekuatan dan kelemahan) dan eksternal (peluang dan ancaman) untuk mengatur strategi dimasa yang akan datang dengan menggunakan analisis SWOT. Strategi yang digunakan perusahaan X yang berada pada kuadran 1 adalah growth oriented strategy, dimana dalam strategi ini pelaku usaha diharapkan agar bisa mempertahankan keadaan usaha yang sudah mulai berkembang [2]. PT. Y adalah sebuah perusahaan dalam menerapkan strategi pemasaran kurang maksimal dikarenakan tidak ada SDM di posisi marketing sehingga menyebabkan penurunan penjualan. Dengan permasalahan yang ada dalam perusahaan maka penelitian menggunakan analisis SWOT. Hasil penelitian ini adalah memperbaiki sistem dan meningkatkan promosi sehingga dapat memperluas target pasar dan juga 
mempertahankan dan meningkatkan kualitas pelayanan terhadap pelanggan dengan tetap mempertahankan relasi bisnisnya [3].

Berdasarkan pada sudut pandang diatas bahwa perusahaan membutuhkan kecepatan inovasi yang didukung oleh kompetensi inti [4], menyatakan bahwa mengarahkan perusahaan pada saat ini melintasi lingkungan persaingan yang kompleks dan rumit.Hal ini menggambarkan bahwa setiap perusahaan harus mempunyai pengetahuan serta strategi usaha yang sesuai dengan jenis usaha yang dikelolanya agar perusahaan tersebut dapat dikendalikan. Selain alasan diatas UKM melihat peluang bahwa kebutuhan gula merah secara nasional belum terpenuhi bisa dilihat dari grafik permintaan gula merah secara nasional dibawah ini :

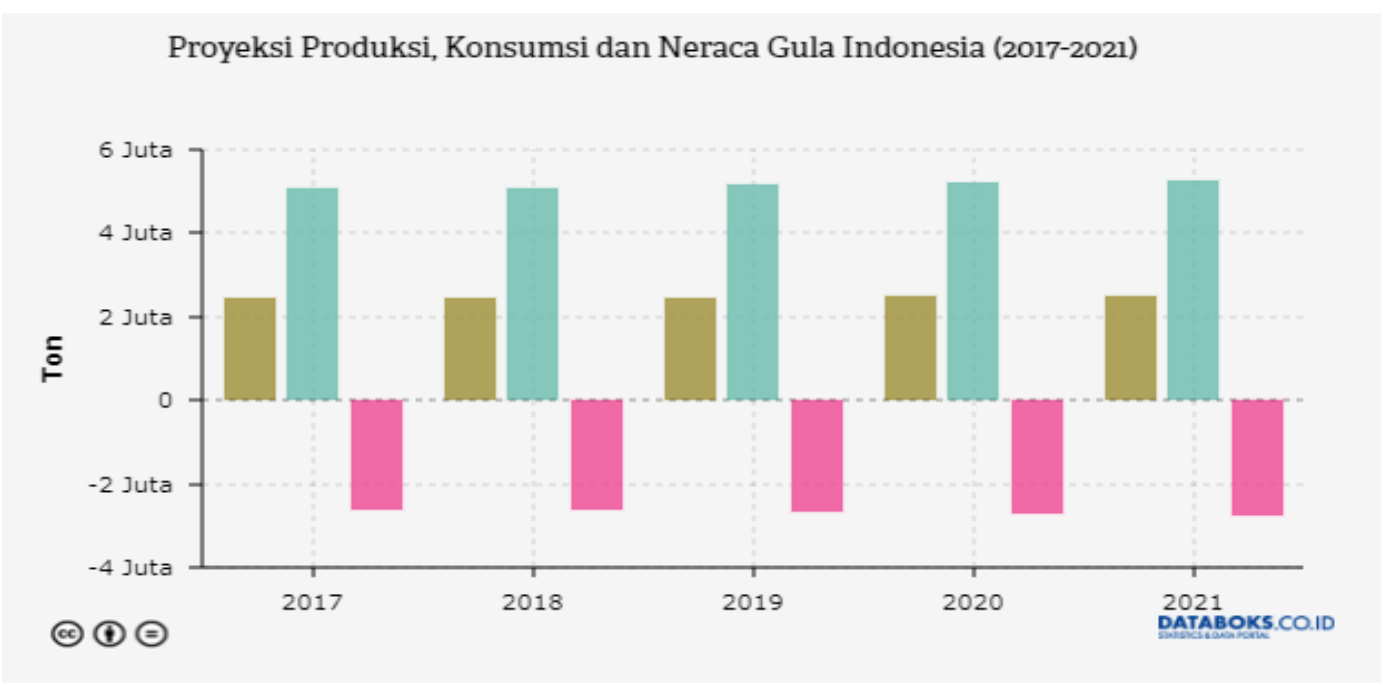

Gambar grafik Permintaan Gula Merah Nasional. Sumber Data : Data Statistik Permintaan Gula Merah Nasional.

Dari grafik diatas menunjukkan bahwa permintaan gula merah nasional per tahun adalah 5 juta ton per tahun, sedangkan yang bisa terpenuhi 2,5juta ton per tahun sisanya belum bisa terpenuhi.Melihat kondisi seperti ini UKM ingin mengisi cerung kebutuhan gula merah secara nasional yaitu $0,002 \%$ dari kebutuhan gula merah secara nasional. Oleh karena itu UKM mempunyai target penjualan 100 ton per bulan.

Melihat kondisi saat ini bahwa dalam menghadapi persaingan yang semakin ketat baik karena pesaing yang semakin bertambah, volume produk yang semakin meningkat, maupun perkembangan teknologi yang pesat, serta banyaknya industri besar yang mulai berdatangan di Kabupaten Tulungagung yang secara tidak langsung berimbas terhadap SDM pembuat gula merah khususnya generasi muda yang memilih bekerja di industri besar dari pada menjadi pekerja gula merah. Oleh karena itu UKM gula merah perlu menerapkan strategi yang lebih tepat untuk bisa meningkatkan penjualan dan dapat bersaing dengan industri-industri lain.

\section{Metode Penelitian}

Penelitian ini menggunakan pendekatan deskriptif, yaitu pengukuran yang cermat terhadap fenomena sosial tertentu.Fenomena tersebut adalah berkenaan dengan strategi peningkatan penjualan. Analisis Strengths, Weakness, Opportunities, and Threats (SWOT), akan dipergunakan untuk mengidentifikasi berbagai faktor secara sistematis, merumuskan strategi, dan selanjutnya menentukan strategi untuk meningkatkan penjualan. Populasi yang diambil dalam penelitian ini yaitu konsumen, pekerja dan pemilik UKM gula merah.Metode yang digunakan dalam penarikan sampel ini adalah random sampling, yaitu pengambilan sampel anggota populasi yang dilakukan secara acak tanpa memperhatikan strata yang ada dalam populasi tersebut.Dengan perincian populasi pekerja 11 orang, manajemen UKM 2 orang, konsumen 150 orang. Kemudian diambil sampel dengan rincian 100 orang konsumen dan 13 orang manajemen UKM sehingga total sampel dalam penelitian ini adalah 113 
orang.Instrumen yang digunakan dalam penelitian ini kuisioner.Metode pengumpulan data yang dilakukan dalam penelitian ini ialah observasi, metode interview dan metode survey. Pembobotan nilai 17, 16, 15, 14, 13, 12 diperoleh dari standart UKM yang sudah settle, UKM yang memiliki jumlah penjualan yang sudah stabil yaitu UD. Restu Ibu milik Bapak Pipit di desa Slumbung Kecamatan Ngadiluwih Kabupaten Kediri.Rata-rata diperoleh dari hasil kuisioner. Misal hasil 1,9 diperoleh dari jumlah skala likert $0,9,12,4$, masing-masing dibagi dengan jumlah responden yaitu $0 / 13=0,9 / 13=$ $0,7,12 / 13=0,9,4 / 13=0,3$ kemudian dijumlahkan $=0+0,7+0,9+0,3=1,9$.

\section{Hasil Penelitian}

Dari hasil penelitian menunjukkan faktor internal dan eksternal adalah sebagai berikut:

Tabel 1 Faktor Internal (kekuatan)

\begin{tabular}{|c|c|c|c|c|}
\hline Item & Faktor Internal & \multirow{2}{*}{ Bobot } & \multirow{2}{*}{$\begin{array}{l}\text { Rata- } \\
\text { Rata }\end{array}$} & \multirow{2}{*}{$\begin{array}{l}\text { Bobot x Rata- } \\
\text { rata }\end{array}$} \\
\hline \multicolumn{2}{|r|}{ Kekuatan (Strenght) } & & & \\
\hline 1. & $\begin{array}{l}\text { UKM melakukan usaha dengan modal } \\
\text { sendiri }\end{array}$ & 17 & 1,9 & 32,3 \\
\hline 2. & UKM tidak memiliki pinjaman & 16 & 1,8 & 28,8 \\
\hline 3. & $\begin{array}{l}\text { Sikap dan perilaku positif pemilik UKM } \\
\text { berpengaruh terhadap kinerja karyawan }\end{array}$ & 15 & 1,4 & 21 \\
\hline 4. & Harga produk di bawah harga pasar. & 14 & 1,4 & 19,6 \\
\hline 5. & Bahan baku terpenuhi. & 13 & 1,6 & 20,8 \\
\hline 6. & Penjualan dapat memenuhi target usaha. & 13 & 1,8 & 23,4 \\
\hline 7. & $\begin{array}{l}\text { Pekerja merupakan orang yang mengetahui } \\
\text { tentang produksi gula merah }\end{array}$ & 12 & 1,8 & 21,6 \\
\hline & TOTAL & 100 & & 167,5 \\
\hline
\end{tabular}

Dari tabel 1 dapat diketahui total dari hasil perkalian antara bobot dikalikan rata-rata 167,52

Tabel 2 Faktor Internal (Kelemahan)

\begin{tabular}{|c|l|c|c|c|}
\hline \multicolumn{2}{|l|}{ Kelemahan (Weaknes) } & Bobot & $\begin{array}{c}\text { Rata- } \\
\text { rata }\end{array}$ & $\begin{array}{c}\text { Bobotxrata- } \\
\text { rata }\end{array}$ \\
\hline 1. & $\begin{array}{l}\text { UKM belum mempunyai jaringan } \\
\text { pemasaran. }\end{array}$ & 19 & 3,3 & 62,7 \\
\hline 2. & Pendanaan tidak melibatkan perbankan. & 18 & 3,4 & 61,2 \\
\hline 3. & Upah tenaga kerja sesai UMR. & 17 & 3,1 & 52,7 \\
\hline 4. & Tidak ada pembinaan dari dinas terkait. & 17 & 3,5 & 59,5 \\
\hline 5. & Fasilitas produksi masih manual. & 15 & 3,6 & 54,49 \\
\hline 6. & $\begin{array}{l}\text { Pekerja tidak tetap berpengaruh pada } \\
\text { produktifitas UKM. }\end{array}$ & 14 & 3,5 & 49 \\
\hline & \multicolumn{1}{|c|}{ TOTAL } & $\mathbf{1 0 0}$ & & $\mathbf{3 3 9 , 1}$ \\
\hline
\end{tabular}

Dari tabel 2 dapat diketahui total dari hasil perkalian antara bobot dikalikan dengan rata-rata 339,1

Tabel 3 Faktor eksternal (Peluang)

\begin{tabular}{|c|l|c|c|c|}
\hline Item & \multicolumn{1}{|c|}{ Faktor } & \multirow{2}{*}{ Bobot } & $\begin{array}{c}\text { Rata- } \\
\text { Rata }\end{array}$ & $\begin{array}{c}\text { Bobot x Rata- } \\
\text { rata }\end{array}$ \\
\hline 1. & $\begin{array}{l}\text { Usaha gula merah masih jarang di } \\
\text { sumber gempol }\end{array}$ & 17 & 2,22 & 37,74 \\
\hline 2. & $\begin{array}{l}\text { Gula merah mempunyai peluang } \\
\text { pasar yang besar }\end{array}$ & 16 & 2,07 & 33,12 \\
\hline 3. & $\begin{array}{l}\text { Pengembangan SDM dapat } \\
\text { meningkatkan jumlah penjualan }\end{array}$ & 15 & 1,82 & 27,3 \\
\hline 4. & $\begin{array}{l}\text { Pesaing UKM gula merah belum } \\
\text { banyak ditembus di sumber gempul }\end{array}$ & 14 & 1,62 & 23 \\
\hline
\end{tabular}




\begin{tabular}{|c|l|c|c|c|}
\hline 5. & $\begin{array}{l}\text { UKM sudah mampu memenuhi } \\
\text { permintaan konsumen }\end{array}$ & 13 & 1,55 & 21 \\
\hline 6. & $\begin{array}{l}\text { Prodk gula merah UKM ini mudah } \\
\text { diperoleh }\end{array}$ & 13 & 1,84 & 23,92 \\
\hline 7. & $\begin{array}{l}\text { Gula merah UKM ini memiliki } \\
\text { kualitas yang bagus }\end{array}$ & 12 & 1,84 & 22,08 \\
\hline & \multicolumn{1}{|c|}{ TOTAL } & $\mathbf{1 0 0}$ & & $\mathbf{1 8 8 , 1 6}$ \\
\hline
\end{tabular}

Dari tabel 3 diperoleh total perkalian antara bobot dikalikan rata-rata adalah 188,16

Tabel 4 Faktor eksternal (Ancaman)

\begin{tabular}{|c|l|c|c|c|}
\hline \multicolumn{2}{|l|}{ Ancaman (Threat) } & Bobot & Rata-rata & $\begin{array}{c}\text { Bobot x Rata- } \\
\text { rata }\end{array}$ \\
\hline 1. & $\begin{array}{l}\text { Banyak pesaing UKM gula merah di } \\
\text { sumber gempol }\end{array}$ & 19 & 3,03 & 57,7 \\
\hline 2. & $\begin{array}{l}\text { Harga bahan baku berpengaruh } \\
\text { terhadap penjualan }\end{array}$ & 18 & 3,06 & 55,08 \\
\hline 3. & $\begin{array}{l}\text { Gula merah UKM ini tidak mudah } \\
\text { diperoleh }\end{array}$ & 17 & 3,33 & 56,61 \\
\hline 4. & Globalisasi pasar & 17 & 3,32 & 56,44 \\
\hline 5. & $\begin{array}{l}\text { Perubahan teknologi berpengaruh pada } \\
\text { penjualan }\end{array}$ & 15 & 3,30 & 49,5 \\
\hline 6. & $\begin{array}{l}\text { Gula merah UKM ini memiliki } \\
\text { kualitas di bawah pesaingnya }\end{array}$ & 14 & 3,32 & 46,48 \\
\hline & \multicolumn{1}{|c|}{ TOTAL } & $\mathbf{1 0 0}$ & & $\mathbf{3 2 1 , 8 1}$ \\
\hline
\end{tabular}

Dari tabel 4 diperoleh total perkalian antara bobot dikalikan rata-rata adalah 321,81. Dari hasil analisa matriks grand strategi diperoleh internal faktor analisis $-171,6$ dan eksternal faktor analisis $-133,65$. Dari hasil tersebut menunjukkan bahwa UKM pada posisi kuadran 4 yang merupakan situasi yang sangat tidak menguntungkan, dimana UKM menghadapi berbagai ancaman dan kelemahan internal.

\section{Kesimpulan}

Dari hasil identifikasi dapat diketahui bahwa UKM pada saat ini berada di posisi kuadran 4 dimana merupakan keadaan yang tidak menguntungkan, dari perhitungan diperoleh hasil $\mathrm{S}=167,5, \mathrm{~W}$ $=339,1$ sehingga diperoleh IFAS $=-171,6$ dan $\mathrm{O}=188,16, \mathrm{~T}=321,81$ sehingga diperoleh EFAS $=-$ 133,65. Kuadran 4 merupakan posisi kritis yaitu UKM memerlukan perbaikan-perbaikan baik faktor internal maupun faktor eksternal.UKM menghadapi berbagai ancaman dan kelemahan internal. Oleh karena itu akan dilakukan perbaikan pada kekuatan dan peluang terutama indikator yang memiliki upaya untuk dapat diperbaiki. Saran bagi peneliti selanjutnya adalah memberikan usulan perbaikan untuk meningkatkan penjualan pada UKM gula merah tersebut.

\section{Daftar referensi}

[1] Gaguk Setiawan, Fuad Achmadi, Prima Vitasari, 2018. "Analisis Peningkatan Penjualan Produk kain Tenun Ikat Dengan Metode Quality Function Deployment (QFD)" Jurnal Teknologi dan Manajemen Industri, Vol.4 No.1, Februari 2018.

[2] Kaplan, Robert S, Norton, David P, 1996. "Balanced Scorecard, Translating Strategy Into Action". Boston-Massachussets : Harvard Bussiness School Press.

[3] Kotler, Armstrong, 2001. Principles of marketing ( $9^{\text {th }}$ Edition). New Jersey : Erlangga.

[4] Lamb, Jr Charles W., Crittenden, Victoria L, Cravens, David W. 2002. Strategic Marketing management Cases $7^{\text {th }}$ Edition. New York : McGraw-Hill Companies. 